\title{
インターナショナルミニシンポジウム
}

\section{Challenges in Pediatric Endoscopic Skull Base Surgery}

\author{
David A. Gudis ${ }^{1,2,3}$ \\ ${ }^{1}$ Chief, Division of Rhinology \& Anterior Skull Base Surgery \\ ${ }^{2}$ Department of Otolaryngology-Head \& Neck Surgery \\ ${ }^{3}$ Columbia University Irving Medical Center \\ New York, NY
}

\begin{abstract}
Pediatric anterior skull base tumors encompass a wide range of pathologies. While they appear infrequently to the clinician, skull base tumors can cause significant damage to vital nearby structures, resulting in significant morbidity and mortality. Historically, pediatric skull base tumors were resected using open transcranial or craniofacial approaches. While the advancement of endonasal endoscopic skull base surgery (ESBS) has improved outcomes and decreased morbidity in adults, these techniques have not yet been
\end{abstract}

widely demonstrated in the pediatric population.

There are unique challenges in the pediatric population including the anatomical confines that restrict restrict surgical instrumentation, the variation of anatomic surgical landmarks, and concern regarding the effects of ESBS on midface development. However, ongoing investigation continues to affirm the role of ESBS in children. This lecture will focus on surgical challenges and nuances of ESBS in the pediatric population. 